\title{
SIXTY YEARS AGO
}

The article which we reprint below appeared in the Journal of May 1910. The author some thirty years ahead of his time, advocates the early ambulation of postoperative surgical patients-a practice which was not fully recognised until the early 1940's.

It is for reflection whether tucked away in the early numbers of the Journal, there are other sound ideas which have not yet been recognised. Ideas, which were formulated, by doctors more dependent on their own powers of observation and with more time to think.

(May 1910)

\section{A PLEA FOR SHORTENING THE PERIOD OF CONFINEMENT TO BED AFTER ABDOMINAL OPERATIONS}

\author{
By Major F. J.: W: PORTER, D.S.O. \\ Royal Army Medical Corps
}

The prevailing custom of keeping patients confined to bed for a period of three weeks appears unsound.

In the Service, the most common abdominal operations are those for the removal of the appendix and the radical cure of hernia. As regards the first operation, it is usually done through a skin incision not exceeding 2 inches in length, close to the anterior superior spine, and the muscles are split in a direction parallel to their fibres. The abdominal wound is closed in layers, and some lasting matelial, such as kangaroo tendon or silk, is generally used.

In the case of the radical cure of hernia, the sac is stripped up as far as the internal ring, ligatured, twisted, pulled up through a hole in the internal oblique, and sutured in the twisted position. The canal is narrowed when necessary, and the superficial structures are securely sutured by a lasting material, care being taken to tighten up the external oblique by rolling it in. The great majority of patients are able (if permitted) to sit up on the third day, and they experience no pain or discomfort in their wounds. Old traditions die hard, but it would appear that strain or damage would evidence itself by pain and discomfort.

During my last tour at Colchester, over 150 removals of the appendix were performed. At first one kept every patient in bed for three weeks. The men became very discontented after the first week, and their general health certainly was not improved by such confinement. I then gradually shortened the period, and seeing no ill-results, eventually let them all get up all day on the eighth day after he operation.

Shortly before I left, I operated on a lady for appendicitis. She was up on the sixth day, and walked two miles on the fourteenth.

Lately I operated on a healthy girl of fifteen years for chronic appendicitis. She sat up in bed on the third day, and got out to have her bed made. On the sixth day she sat in a deck chair for twelve consecutive hours. She walked about after the seventh day, and rode her bicycle at the end of the third week.

Under such a plan of treatment, the muscles, especially those of the back and legs, do not waste, as they certainly will do if not used for three weeks, and no time is lost in convalescence. 
As regards hernia, I see no reason against a similar line of action. If one can depend on the strength and lasting properties of the suture material one uses, and the patient refrains from trying to lift weight for at least three months after the operation, there can be no risk in allowing him up even before the sixth day.

There is another fallacy which also requires exploding. I refer to the custom of not allowing ordinary patients to turn themselves in bed for several days after an abdominal operation. It hurts a patient far less to allow him to turn himself over in bed, than if he is seized by the hips and shoulders and turned by a nurse. In the former case, he instinctively keeps the damaged section of his abdomen quite rigid, and the absence of pain during the movement is, I think, a proof that no injury is being sustained.

WITH PEGASUS

IN INDIA

The Story of 153 Gurkha Parachute Battalion

by

ERIC NEILD

WE have received a copy of this most interesting and entertaining book and a review will appear in our next issue. Meantime we commend it to all who have served with Gurkha troops, to those who are interested in service history and to those who just like a good straightforward and well told story.

All profits resulting from the sale of copies are being donated to the Gurkha Welfare Appeal.

This book, which is most attractively produced, costs $£ 1.0 \cdot 0$ and is available from Colonel F. G. Neild, L/R.A.M.C., Army School of Health, Keogh Barracks, Ash Vale, Nr. Aldershot, Hants.

Cheques should be made payable to Colonel F. G. Neild, 